\title{
Erratum
}

\section{Molecular characterization of apoptosis induced by CARF silencing in human cancer cells}

CT Cheung, R Singh, AR Yoon, MK Hasan, T Yaguchi, SC Kaul, CO Yun and R Wadhwa

Cell Death and Differentiation (2011) 18, 1238; doi:10.1038/cdd.2011.68

Correction to: Cell Death and Differentiation (2011) 18, 589-601; doi:10.1038/cdd.2010.129

Since the publication of this article, the authors noticed that the labeling in Figure 7a appeared incorrect. The correct labeling is shown below.

a

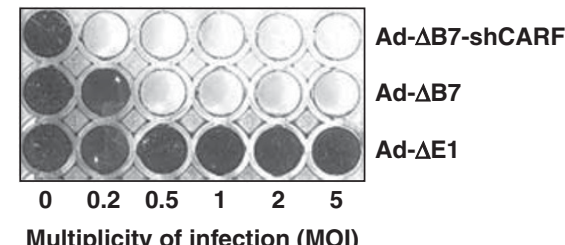

We would like to apologize for any inconvenience this may have caused. 